\title{
Compositional Optimization of Chalcogenide Glasses for Use as Imaging Lenses in the Long-Wavelength Infrared Range
}

\author{
Jun Ho Lee, Hyun Kim, Yong Gyu Choi ${ }^{\dagger}$
}

Department of Materials Science and Engineering, Korea Aerospace University, Goyang, Gyeonggi 10540, Republic of Korea

\section{원적외선 대역 결상 렌즈용 칼코지나이드 유리의 조성 최적화}

\author{
이준호, 김현, 최용규 ${ }^{\dagger}$ \\ 한국항공대학교 항공재료공학과
}

(Received August 22, 2020; Revised September 3, 2020; Accepted September 4, 2020)

\begin{abstract}
Demand on thermal camera capable of visualizing spatial distribution of infrared radiation especially in the long-wavelength infrared (LWIR; 8-12 $\mu \mathrm{m}$ ) range is rapidly increasing in diverse civilian sectors including, for example, mobile electronic devices like smartphone. Unlike the traditional military applications, not only size miniaturization and performance enhancement but also cost reduction becomes more crucial in these civilian applications. As such, as compared with its crystalline counterparts, chalcogenide glass turns out to be more promising as LWIR-transmitting lenses working in numerous civilian sectors in view of its inherent compositional flexibility as to adjusting thermal and optical properties. In addition, its viscoelasticity upon mechanical loading at a proper temperature makes it much more competitive in saving processing cost: Specifically, chalcogenide glass lenses can be mass-produced via precision glass molding (PGM) technique. Optical characteristics prioritized in lens performance can also be engineered via compositional finetuning over a wide glass forming region reaching far off-stoichiometric compositions. These merits enable extra degrees of freedom in designing lens assembly well-functioning to a desired level of performance. In this article, we employ ternary Ge-Sb-Se glass as a representative chalcogenide glass for the LWIR lens applications, and review its composition-dependent behaviors of thermal, mechanical and optical properties. These experimentally verified compositional dependences are then elucidated in terms of unempirical
\end{abstract}

${ }^{\dagger}$ Corresponding Author: Yong Gyu Choi

E-mail: ygchoi@kau.ac.kr 
glass structure related parameters in an effort to provide guidelines for compositional engineering of other chalcogenide glasses. In addition, we present some exemplary cases of compositional optimization applied to chalcogenide glasses containing $\mathrm{Ge}$ and $\mathrm{Sb}$, which are mainly aimed at broadening the LWIR Abbe diagram towards the high-dispersion side.

Keywords: Chalcogenide glass, Infrared lens, Thermal camera, Precision glass molding, Wafer level optics

\section{1. 서론}

열화상 카메라는 물체로부터 방출되는 적외선 대역의 파장을 가지는 전자기파를 시각 이미지로 구현하는 결 상 광학계로서 크게 렌즈, 이미지 센서 및 신호처리부로 구성된다. 흑체복사 법칙에 의하면, 서로 다른 온도의 피사체는 서로 다른 파장의 전자기파를 방출하기 때문 에 열화상 카메라는 피사체의 형태를 구분하는 것과 더 불어 비접촉 방식으로 피사체의 온도 정보를 획득할 수 있다. 적외선 파장 대역 중에서 대기에 존재하는 분자 들의 공명 진동흡수에 의한 손실 발생이 적은 중적외선 (3-5 $\mu \mathrm{m})$ 대역과 원적외선 $(8-12 \mu \mathrm{m})$ 대역을 '대기의 광 학적 투과창'으로 분류할 수 있으며 ${ }^{1)}$, 따라서 열화상 카 메라는 해당 파장 대역을 활용하는 것이 바람직하다. 근 적외선 대역의 경우에는 흑체복사로 방출된 광자를 활 용하기 위해서는 매우 고온의 피사체를 요구하기 때문 에 일반적으로 흑체복사를 활용하기보다는 근적외선 광 원을 조명으로 활용하여 피사체의 반사광 분포를 가시 화하며, 결과적으로 온도분포 감지에는 적합하지 않달. 즉, 열화상 카메라는 '대기의 광학적 투과창' 중에서 중 적외선(MWIR; mid-wavelength infrared) 카메라와 원적외선(LWIR; long-wavelength infrared) 카메라 로 분류할 수 있다. 사람의 체온과 같은 온도 대역에서 흑체복사는 $\sim 10 \mu \mathrm{m}$ 파장에서 최대강도를 방출하므로 중적외선 카메라보다 원적외선 카메라가 민수 분야에서 수요가 증가하고 있다 ${ }^{3-5)}$. 특히, 기존 군수 분야와 더불 어 보안 ${ }^{6)}$, 비파괴 검사 ${ }^{7,8)}$, 안전,10), 차량용 나이트 비전 5,11-13) 등의 매우 다양한 민수 분야에서 원적외선 카메라
의 용도가 폭증하는 추세에 있다. 최근에는 열화상 카메 라가 스마트폰과 같은 이동형 전자기기에 부착되는 수 준으로 크기가 현저히 작아지고 있기 때문에 향후 스마 트폰에 직접 내장되는 수준으로 소형화 및 고성능화가 이루어져 더욱 다양한 분야에서 응용될 것으로 전망된 다 ${ }^{14,15)}$. 민수분야 적용을 위한 열화상 카메라의 경우 일 반적인 군수용 열화상 카메라 대비 소형화 및 가격경쟁 력이 매우 중요한 인자로 작용한다. 열화상 카메라의 가 격경쟁력 측면에서 비냉각식 볼로미터(bolometer) 방식 의 이미지 센서가 적합하며하), 렌즈의 경우 결정질 소재 보다 칼코지나이드 유리소재가 유망하다 ${ }^{17)}$. 특히, 광학 렌즈로서 결정질 소재는 Table 1에 제시한 바와 같이 열 적, 기계적 물성이 우수하지만 렌즈 제작에 있어 다이아 몬드 선삭 가공(DTM; diamond turning machining) 과 같은 정밀 직가공 공정이 필요하기 때문에 양산성이 떨어지는 단점을 가지게 된다 ${ }^{18)}$.

칼코지나이드 유리소재는 유리전이온도 이상의 적절 한 온도에서 점탄성 거동을 보이기 때문에 렌즈 제작에 있어 직가공 방식 성형공정과 더불어 몰딩 방식 성형공 정의 적용이 가능하여 양산성 측면에서 가격 경쟁력이 매우 뛰어나다. 더욱이 칼코지나이드 유리소재의 경우, 결정질 소재와 달리, 유리형성 영역 내에서 조성 변화 를 통하여 물성을 제어할 수 있기 때문에 다양한 물성을 가지는 조성을 확보할 수 있다 ${ }^{22)}$. 이러한 장점을 활용하 면, 굴절률을 향상시켜 렌즈부의 두께를 줄일 수 있으며 ${ }^{23)}$, 나아가 다양한 굴절률 및 굴절률 분산을 가지는 렌 즈들을 조합하여 광학 수차가 보정된 고성능 결상 광학 계를 구현할 수 있다 ${ }^{24,25)}$. 종합하면, 칼코지나이드 유리 
Table 1. Thermal, mechanical and optical properties of representative LWIR-transmitting materials, ${ }^{5,19-21)}$

\begin{tabular}{|c|c|c|c|c|c|}
\hline Material & $n_{10}$ & $v_{10}^{\dagger}$ & $\frac{d n}{d T}$ & $\begin{array}{c}T E C^{\dagger} \\
\left(\times 10^{-6} / \mathrm{K}\right)\end{array}$ & $\begin{array}{l}K H^{\S} \\
(\mathrm{GPa})\end{array}$ \\
\hline $\begin{array}{l}\text { Single-crystalline } \\
\text { Ge }\end{array}$ & 4.003 & 986 & 396 & 5.9 & 10.0 \\
\hline Polycrystalline ZnS & 2.200 & 23 & 54 & 6.5 & 2.5 \\
\hline Polycrystalline ZnSe & 2.407 & 58 & 60 & 7.0 & 1.0 \\
\hline $\begin{array}{c}\text { Glassy } \mathrm{Ge}_{28} \mathrm{Sb}_{12} \mathrm{Se}_{60} \\
\text { (at.\%) }\end{array}$ & 2.603 & 109 & 59 & 14.0 & 1.1 \\
\hline
\end{tabular}

${ }^{\dagger}$ LWIR Abbe number, i.e., refractive index dispersion in the LWIR range calculated using $\nu_{10}=\frac{n_{10}-1}{n_{8}-n_{12}}$ where $n_{8}, n_{10}$ and $n_{12}$ denote refractive indexes measured at $8 \mu \mathrm{m}, 10 \mu \mathrm{m}$ and $12 \mu \mathrm{m}$, respectively.

${ }^{*}$ Thermal expansion coefficient

$\S$ Knoop hardness

는 소재 특성상 가격 경쟁력이 우수하고 물성 조절을 통 해 열화상 카메라 모듈의 소형화 및 성능향상을 동시에 도모할 수 있다는 장점을 가진다. 본 논문에서는 칼코 지나이드 유리가 가지는 상기 장점들을 최대로 활용하 는 적외선 렌즈용 광학소재의 개발을 위한 조성 최적화 방법론을 예시적으로 보이고자 한다. 특히, 칼코지나이 드 유리의 열적, 기계적, 광학적 물성의 조성 의존성을 실험적으로 파악하고 이러한 결과를 유리구조 관점에서 해석한 결과를 제시하였으며, 나아가 새로운 굴절률/분 산 특성을 가지는 유리조성의 확보를 위하여 상용 $\mathrm{Ge}-$ $\mathrm{Sb}-\mathrm{Se}$ 조성 시스템을 대상으로 이루어진 조성설계 사 례를 소개하고자 한다.

\section{2. 적외선 렌즈용 칼쿄지나이드 유리}

칼코지나이드 유리는 주기율표 6족의 원소들 중에서 산소 $(\mathrm{O})$ 를 제외한 황 $(\mathrm{S})$, 셀레늄( $\mathrm{Se})$ 및 텔루륨 $(\mathrm{Te})$ 의 칼코진 원소를 하나 이상 포함하는 이성분계 이상의 조 성계로 구성된 유리소재를 의미한다. 실리케이트 유리 와 같은 일반적으로 잘 알려진 산화물 유리소재는 구성 원자간 이온 결합성이 상대적으로 강하기 때문에 각 출 발물질이 화학양론비를 만족하는 화합물 형태를 가져야 하며 이의 조합으로부터 안정한 유리 상태가 형성되고,
각 구조 단위의 전하보상이 유리 네트워크의 형태에 중 요한 영향을 미친다. 칼코지나이드 유리에서는 구성원 자 사이의 전기음성도 차이가 작고 공유 결합성이 상대 적으로 크기 때문에 일례로 $\mathrm{Ge}-\mathrm{Ge}$ 또는 $\mathrm{Se}-\mathrm{Se}$ 결합과 같은 동종결합이 형성될 수 있다라이이리난 이유로 칼코 지나이드 조성 시스템은 2 성분 조성계를 포함하여 화 학양론비 조성을 벗어나는 비교적 넓은 영역에서 안정 한 유리 상태를 형성할 수 있으며, 화학양론비 변화에 따른 이종결합/동종결합의 비율 변화 및 평균 배위수 등 의 구조인자를 활용하여 유리구조 변화에 대한 제반 물 성의 변화를 설명할 수 있달). 또한, Fig. 1(a)에서 볼 수 있듯이 일반적인 산화물 유리는 대개 $\sim 5 \mu \mathrm{m}$ 수준에 서 적외선 투과단이 형성되는 반면에 칼코지나이드 유 리는 원적외선 대역보다 긴 파장에서 투과단이 형성될 수 있다. 적외선 대역 투과단은, 전자 천이에 의해 결 정되는 가시광 대역 투과단과 달리, 구성원자 사이에서 발생하는 진동 천이의 다중포논 흡수(multi-phonon absorption) 현상에 의해 발생되는데 ${ }^{27)}$, 산화물 유리 는 상대적으로 가벼운 원소들로 구성되고 구성원자 사 이의 결합이 상대적으로 강하기 때문에 Fig. 1(b)에 도 시한 라만 스펙트럼과 같이 진동 에너지 준위 간격이 넓 다. 이와는 다르게 칼코지나이드 유리는 비교적 무거운 원소들로 구성되고 상대적으로 약한 결합으로 유리구조 를 형성함에 따라 적외선 대역의 공명 흡수가 긴 파장대 역에 위치하게 된다. 칼코진 원소가 $\mathrm{S}, \mathrm{Se}, \mathrm{Te}$ 으로 변화 하면서 해당 원자를 포함하는 유리의 적외선 투과단이 긴 파장 방향으로 이동하는 것을 관찰할 수 있다. 이와 동시에 투과창 범위에서 산란 및 불순물에 기인하는 흡 수가 없을 때의 투과도는 굴절률이 커지면서 낮아지기 때문에 일반적으로 텔루라이드(telluride) 셀레나이드 (selenide) < 설파이드(sulfide) <옥사이드(oxide) 순으 로 투과도가 증가하는 경향을 보인다 ${ }^{26)}$.

상기한 바와 같은 고유한 특성에 의거하여 $\mathrm{As}_{-}-\mathrm{S}$, $\mathrm{Se}), \mathrm{Ge}-(\mathrm{As}, \mathrm{Sb})-(\mathrm{Se}, \mathrm{Te})$ 조성계를 바탕으로 상용화 가 이루어졌으며, 원적외선 대역 광학렌즈로 활용되고 있다. Table 2에서 현재 시판되고 있는 대표적인 칼코지 나이드 유리를 조성계별로 구분하여 유리전이온도, 열 

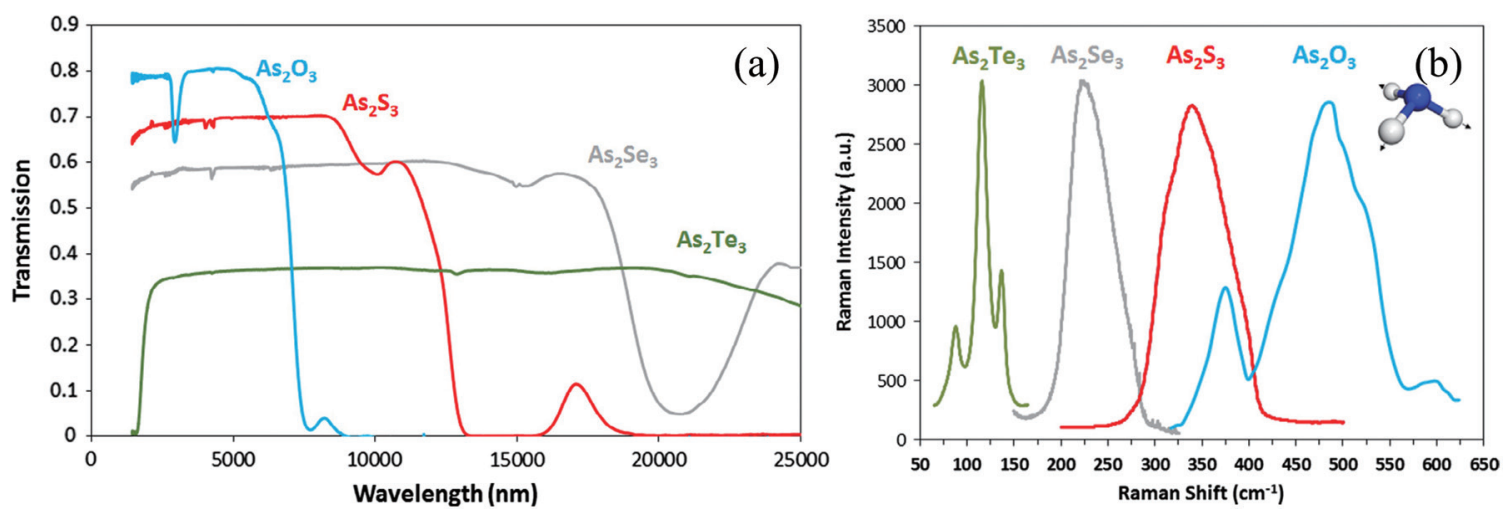

Fig. 1. (a) Transmission and (b) Raman spectra of As-based binary chalcogenide and oxide glasses ${ }^{28}$. Reproduced with permission. Copyright 2015, Elsevier.

Table 2. Thermal and optical properties of some commercially available chalcogenide glasses for use as LWIR molded lenses

\begin{tabular}{c|c|c|c|c|c}
\hline \multirow{2}{*}{ Glass forming system } & \multirow{3}{*}{ Composition (at.\%) } & \multicolumn{4}{|c}{ Material properties } \\
\cline { 3 - 6 } & & $\begin{array}{c}T_{g}^{\dagger} \\
\left({ }^{\circ}\right)\end{array}$ & $\begin{array}{c}\text { TEC } \\
\left(10^{-6} / \mathrm{K}\right)\end{array}$ & $n_{10}$ & $v_{10}$ \\
\hline \multirow{2}{*}{$\mathrm{As}-\mathrm{Se}$} & $\mathrm{As}_{40} \mathrm{Se}_{60}$ & 185 & 20.8 & 2.7782 & 160.2 \\
\hline \multirow{2}{*}{$\mathrm{Ge}-\mathrm{As}-\mathrm{Se}$} & $\mathrm{Ge}_{10} \mathrm{As}_{40} \mathrm{Se}_{50}$ & 225 & 20.4 & 2.6090 & 174.9 \\
\cline { 2 - 6 } & $\mathrm{Ge}_{22} \mathrm{As}_{20} \mathrm{Se}_{58}$ & 292 & 17.0 & 2.4944 & 119.6 \\
\cline { 2 - 6 } & $\mathrm{Ge}_{33} \mathrm{As}_{12} \mathrm{Se}_{55}$ & 368 & 12.1 & 2.4967 & 110.9 \\
\hline \multirow{2}{*}{$\mathrm{Ge}-\mathrm{Sb}-\mathrm{Se}$} & $\mathrm{Ge}_{20} \mathrm{Sb}_{15} \mathrm{Se}_{65}$ & 285 & 15.5 & 2.5858 & 99.1 \\
\cline { 2 - 6 } & $\mathrm{Ge}_{28} \mathrm{Sb}_{12} \mathrm{Se}_{60}$ & 285 & 14.0 & 2.6032 & 109.1 \\
\hline \multirow{2}{*}{$\mathrm{Ge}-\mathrm{As}-\mathrm{Se}-\mathrm{Te}$} & $\mathrm{Ge}_{30} \mathrm{As}_{13} \mathrm{Se}_{32} \mathrm{Te}_{25}$ & 275 & 13.4 & 2.7869 & 167.0 \\
\hline
\end{tabular}

${ }^{\dagger}$ Glass transition temperature

팽창계수, 굴절률, 굴절률 분산을 정리하였다.

\section{3. 칼쿄지나이드 유리 물성의 조성 의존성}

광학렌즈로의 응용을 위하여 중요하게 다뤄지는 칼코 지나이드 유리의 열적, 기계적, 광학적 물성의 조성 의 존성을 실험적으로 규명하고, 이를 유리구조 관점에서 분석한 사례를 소개하고자 한다. 이를 위하여 대표적인 삼성분계 $\mathrm{Ge}-\mathrm{Sb}-\mathrm{Se}$ 조성계를 채택하였으며, 넓은 범 위의 조성영역을 대상으로 다수의 조성을 용융/급냉법 을 통해 벌크 유리시편으로 제작한 후 물성평가를 진행 하였다 ${ }^{29)}$.

\section{3-1. 열적/기계적 물성의 조성 의존성}

렌즈용 광학유리가 나타내는 경도와 같은 기계적 물 성 및 유리전이 온도, 결정화 온도, 열팽창 계수와 같은 열적 물성은 렌즈 자체의 내구성뿐만 아니라 몰딩성형 공정의 수율과 렌즈 성능에 직접적인 영향을 미치기 때 문에 세심하게 제어되어야 한다. 유리소재 고유의 무질 서한 원자배열 특성으로 인하여 이러한 열적/기계적 물 성의 조성 의존성을 이론적으로 예측하는 것은 매우 어 려우며, 대개의 경우 실험과 이론을 적절히 반영한 반경 험적 접근을 통하여 조성 의존성을 파악하게 된다.

열적/기계적 물성의 조성 의존성을 체계적으로 분석 하기 위하여 삼성분계 $\mathrm{Ge}-\mathrm{Sb}-\mathrm{Se}$ 유리를 대상으로 실 험적으로 측정한 해당 물성을 Fig. 2에 등고선 형태로 증감 경향을 가시화하였다. 유리전이 온도 $\left(T_{g}\right)$ 와 비커스 

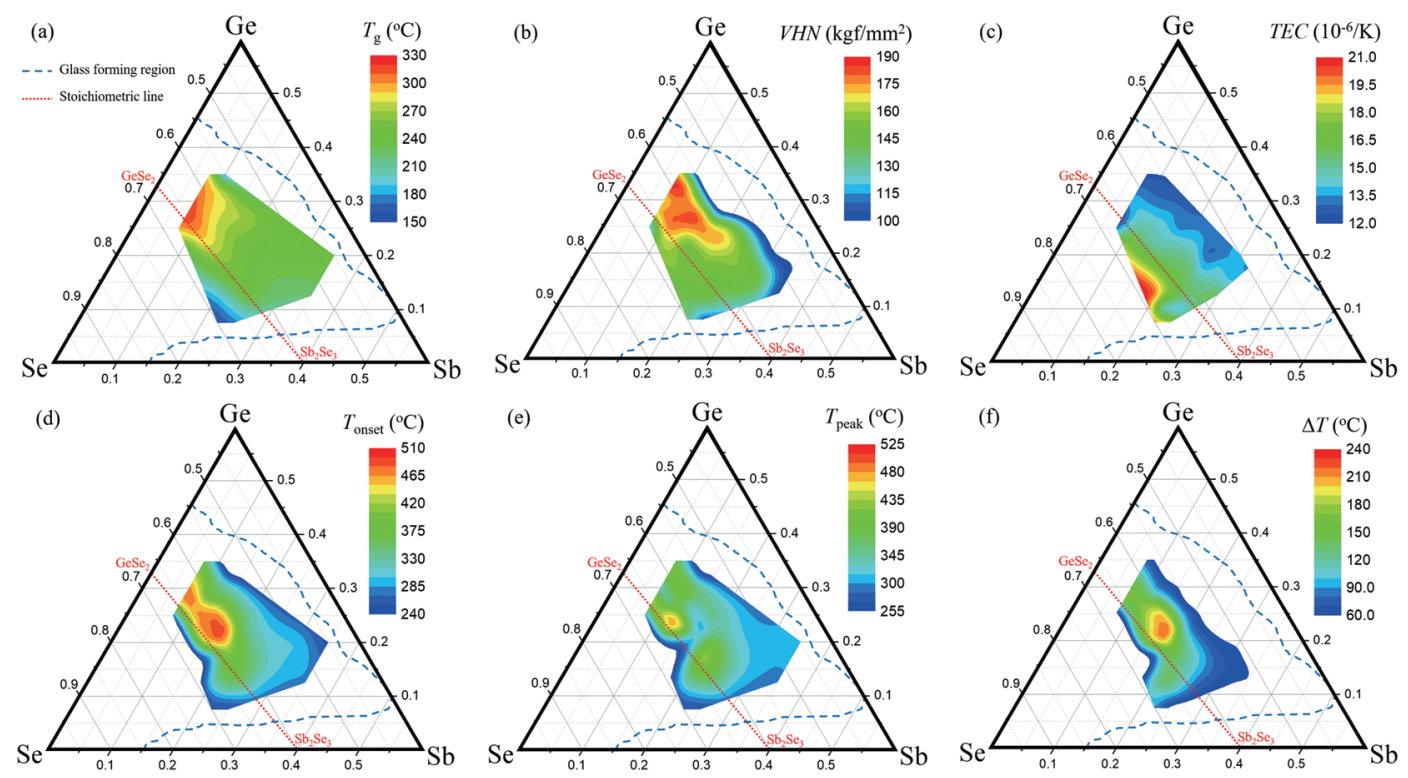

Fig. 2. Composition-dependent behaviors of ternary Ge-Sb-Se glasses: (a) glass transition temperature $\left(T_{g}\right)$, (b) micro-Vickers hardness $(V H N)$, (c) thermal expansion coefficient $(T E C),(d)$ the onset temperature of crystallization ( $\left.T_{\text {onset }}\right)$ (e) the peak temperature of crystallization $\left(T_{\text {peak }}\right)$ and $(f)$ thermal stability $\left(\Delta T\right.$; given by $\left.T_{\text {onset }}-T_{g}\right)$. The data used in these diagrams are adopted from Ref. 30 for $T_{g}$; Ref. 31 for $V H N$; Ref. 32 for TEC; Ref. 33 for $T_{\text {onset, }} T_{\text {peak }}$ and $\Delta T$. The glass forming region presented above is cited from Ref. 22.

경도 $(V H N)$ 는 대략적으로 $\mathrm{Ge}$ 함량에 비례하여 향상되는 경향을 확인할 수 있으며, 열팽창 계수 $(T E C)$ 는 주로 $\mathrm{Se}$ 함량이 감소할수록 향상되는 경향을 확인할 수 있다. 한 편, 본 삼성분계 유리의 결정화 관련 특성 온도는 화학 양론비를 기준으로 $\mathrm{Se}$ 함량이 부족한 특정 조성영역에 서 높아지는 경향이 관찰된다.

이러한 경향을 각 구성원자의 함량변화에 대하여 파 악하고자 하였으며, Fig. 3에 해당 결과를 도시하였다. 비커스 경도와 유리전이 온도의 경우 $\mathrm{Sb}$ 및 $\mathrm{Se}$ 함량에 대하여 0.4 이하 수준의 상관성을 보이는 반면 $\mathrm{Ge}$ 함 량에 대하여 0.7 초과 수준의 높은 상관성을 나타낸다. 열팽창 계수는 $\mathrm{Ge}$ 및 $\mathrm{Sb}$ 함량에 대하여 0.4 이하 수준 의 상관성을 보이지만 $\mathrm{Se}$ 함량에 대하여 0.6 이상의 상 관성을 보인다. 따라서 본 삼성분계 $\mathrm{Ge}-\mathrm{Sb}-\mathrm{Se}$ 유리의 열적/기계적 물성에 가장 큰 영향을 미치는 구성원소는 $\mathrm{Ge}$ 임을 알 수 있다. 한편, 열팽창 계수는 $\mathrm{Se}$ 함량이 가 장 큰 영향을 미치는 것으로 드러났는데, 이는 $\mathrm{Se}$ 원자 의 배위수가 2 로 고정되는 상황에서 $\mathrm{Se}-\mathrm{Se}$ 동종결합이
형성되는 경우 선형적인 사슬 구조를 만들기 때문인 것 으로 판단된다. 화학양론비를 기준으로 $\mathrm{Se}$ 결핍 조성과 $\mathrm{Se}$ 과잉 조성 영역을 나누어 살펴보면, 전반적으로 $\mathrm{Se}$ 결핍 조성이 $\mathrm{Se}$ 과잉 조성보다 우수한 물성을 가지는 경 향이 관찰된다.

각 구성원소에 대한 특정 물성의 겉보기 경향성은 칼코지나이드 유리의 네트워크 구조를 대변하는 평 균 배위수( $M C N$; mean coordination number)와 평 균 결합에너지( $A B E$; average bond energy)를 활용 하여 보다 체계적으로 설명할 수 있음을 확인하였다. 평균 배위수는 임의로 주어진 $\mathrm{Ge}_{x} \mathrm{Sb}_{y} \mathrm{Se}_{z}$ 조성에서(단, $x+y+z=1)$ 각 원소의 최근접 원자 배위수 $(N)$ 에 대하여 $M C N=x N_{G e}+y N_{S b}+z N_{S e}$ 관계식을 통해 계산할 수 있다. 여기에서 $\mathrm{Ge}, \mathrm{Sb}, \mathrm{Se}$ 원자의 배위수는 각각 $4,3,2$ 로 조성변화와 무관하게 일정하게 유지되는 것이 확인되었 다 ${ }^{34,35)}$. 평균 배위수는 유리구조의 토폴로지(topology) 측면을 반영하여 네트워크 구조의 연결도를 대변하며, 평균 배위수가 증가할수록 유리구조의 기계적 변형이 

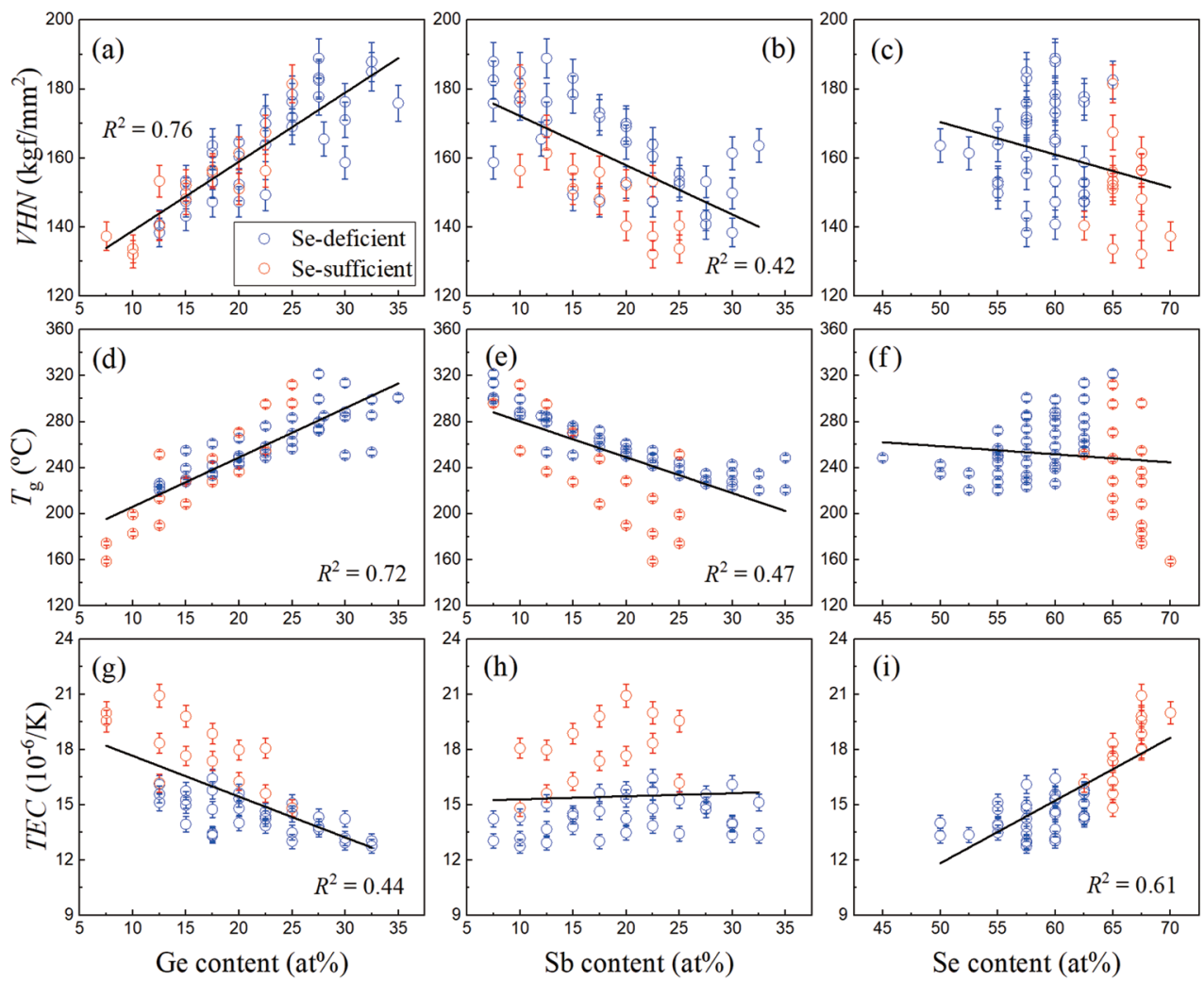

Fig. 3. Changes of micro-Vickers hardness plotted as a function of (a) Ge content; (b) Sb content; (c) Se content. Changes of glass transition temperature plotted as a function of (d) Ge content; (e) Sb content; ( $f$ ) Se content. Thermal expansion coefficient plotted as a function of (g) Ge content; (h) Sb content; (i) Se content. Note that the black straight lines are obtained from least-squares fits, and the corresponding $R^{2}$ values are present inside each graph if necessary. The compositions are divided into two categories based on the stoichiometry of each composition. Here, compositions on the stoichiometric $\mathrm{GeSe}_{2}-\mathrm{Sb}_{2} \mathrm{Se}_{3}$ tie-line are put into the Se-sufficient category.

어려워지는 것으로 이해할 수 있다. 평균 결합에너지는 유리구조의 에너지 측면을 반영하는 인자로 간주할 수 있으며, 유리구조에 참여하는 각 원자가 서로 얼마나 강 하게 결합되어 있는지를 수치화한다고 볼 수 있다. 평균 결합에너지는 유리구조를 구성하는 각각의 화학결합 에 너지를 조성비에 따라 평균하여 계산할 수 있다 ${ }^{35-37)}$. 이 때, 각 화학결합은 전적으로 화학적 선호도를 만족하는 것으로 전제하며, 이에 따라 $\mathrm{GeSe}_{2}-\mathrm{Sb}_{2} \mathrm{Se}_{3}$ 화학양론비 적 조성에서는 $\mathrm{Ge}-\mathrm{Se}$ 및 $\mathrm{Sb}-\mathrm{Se}$ 에 해당되는 이종결합 만 존재하는 것으로 간주한다. Fig. 4에 나타낸 바와 같 이 경도, 유리전이 온도 및 열팽창 계수는 평균 배위수 와 유의미한 상관관계를 가지는 것을 알 수 있다. 여기 에서 유리 조성을 화학양론비를 기준으로 구분하여 분
석하면, $\mathrm{Se}$ 결핍 조성영역에서는 $\mathrm{Ge}-\mathrm{Se}$ 및 $\mathrm{Sb}-\mathrm{Se}$ 이 종결합을 형성하고 남는 여분의 원자들이 $\mathrm{Ge}-\mathrm{Ge}$ 또는 $\mathrm{Sb}-\mathrm{Sb}$ 동종결합을 형성하며, $\mathrm{Se}$ 과잉 조성영역에서는 이종결합과 함께 $\mathrm{Se}-\mathrm{Se}$ 동종결합이 존재하므로 해당 물성의 평균 배위수에 대한 의존성은 추가적으로 화학 양론비를 기준으로 세분화될 수 있다.

평균 배위수의 경우, $\mathrm{Se}$ 원자의 배위수가 $\mathrm{Ge}$ 및 $\mathrm{Sb}$ 원자의 배위수보다 작기 때문에 $\mathrm{Se}$ 결핍 조성과 $\mathrm{Se}$ 과잉 조성의 평균 배위수가 비교적 명확하게 구분된다. 그러 나 평균 결합에너지의 경우, 이종결합 에너지가 대체적 으로 동종결합 에너지보다 크기 때문에 평균 결합에너 지 자체로 화학양론비를 기준으로 나뉜 조성영역을 구 분하기가 어렵다. Fig. 5 에서 이러한 경향을 확인할 수 

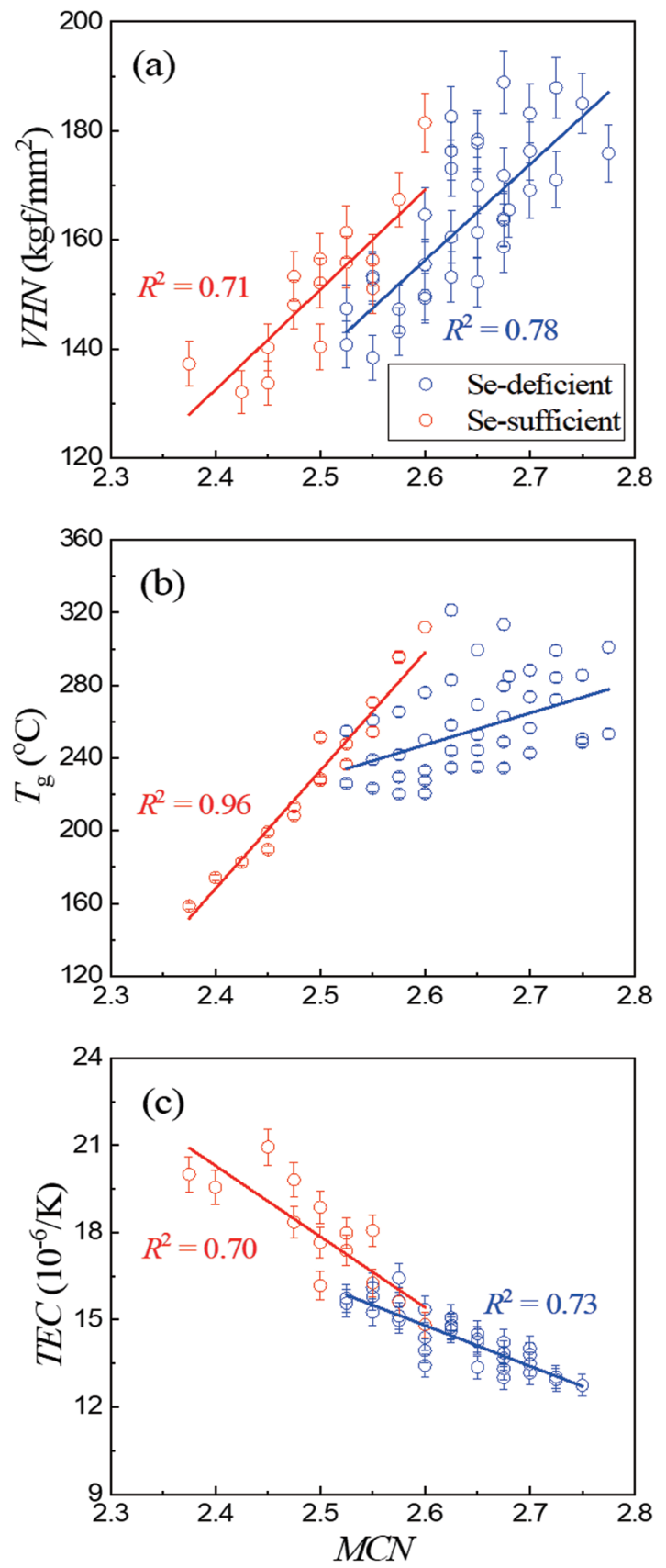

Fig. 4. Changes of (a) micro-Vickers hardness, (b) glass transition temperature and (c) thermal expansion coefficient of ternary $\mathrm{Ge}-\mathrm{Sb}$-Se glasses plotted as a function of mean coordination number.

있으며, 평균 결합에너지 또한 평균 배위수와 유사하게 전반적으로 각 물성에 대한 의존성을 가지는 것을 관찰
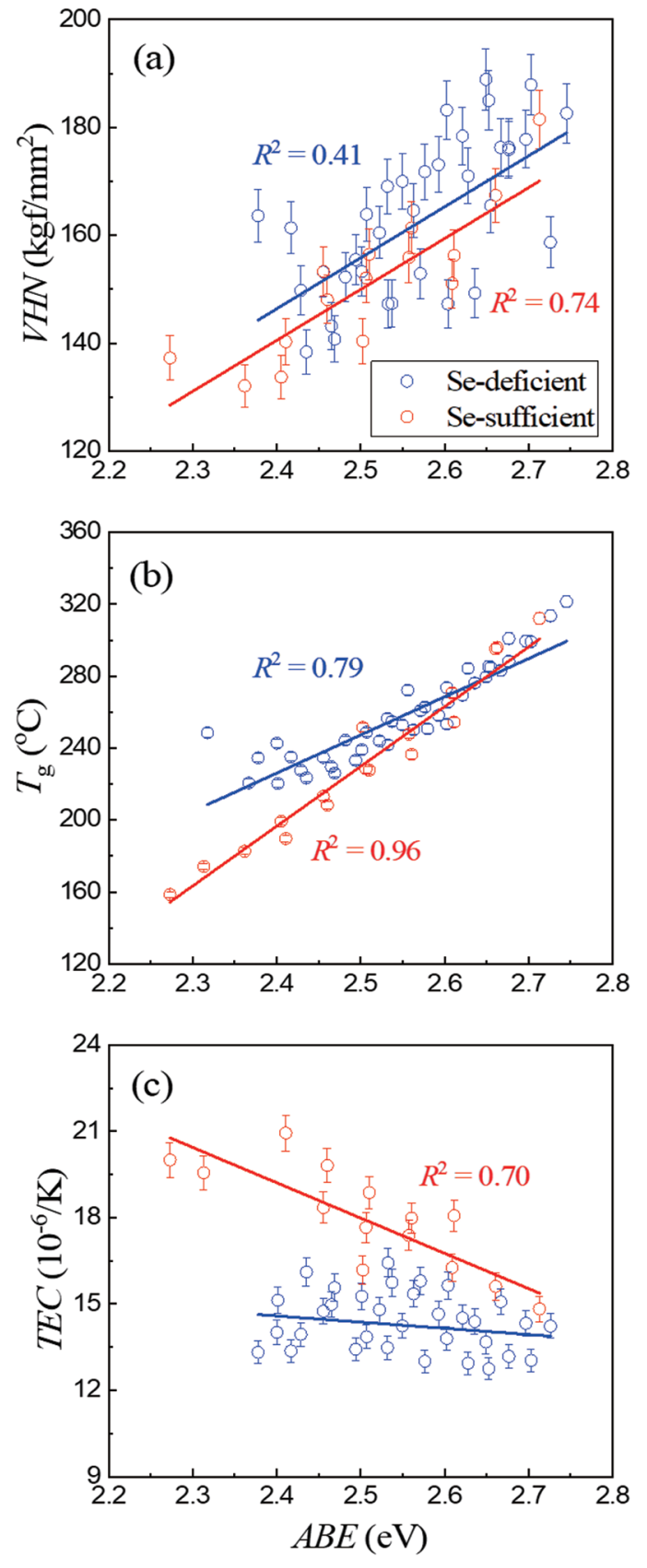

Fig. 5. Changes of (a) micro-Vickers hardness, (b) glass transition temperature and (c) thermal expansion coefficient of ternary $\mathrm{Ge}-\mathrm{Sb}$-Se glasses plotted as a function of average bond energy.

할 수 있다. 한편, 열팽창 계수는 평균 배위수에 대하여 $\mathrm{Se}$ 결핍 조성과 $\mathrm{Se}$ 과잉 조성 공히 0.7 수준의 상관관계 

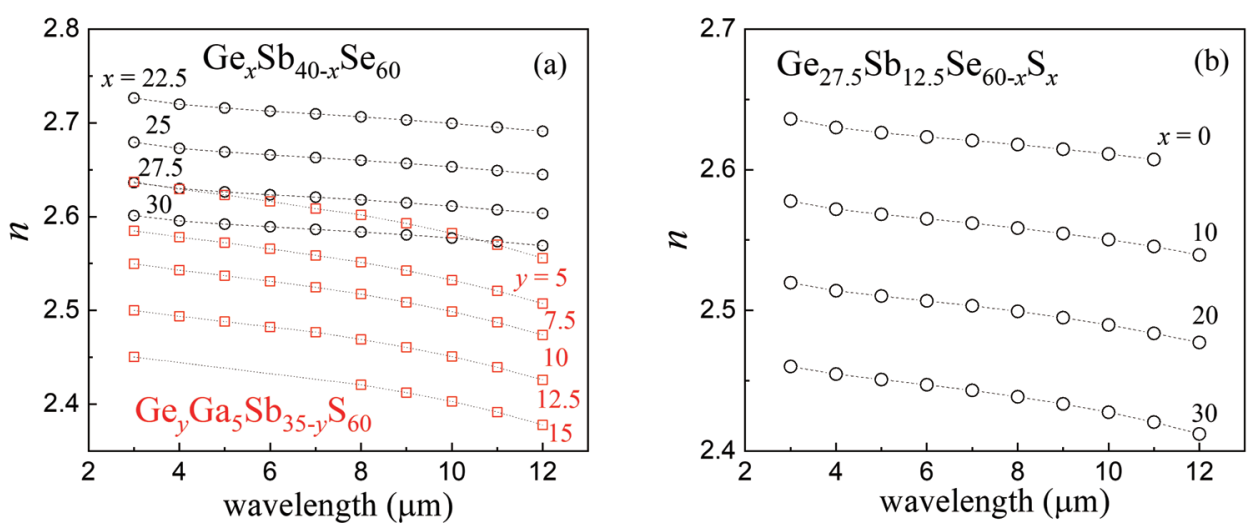

Fig. 6. Measured refractive indexes of (a) ternary Ge-Sb-Se and quaternary Ge-Ga-Sb-S glasses; (b) quaternary Ge-Sb-S-Se glasses. Note that the dotted line segments are simply connecting the adjacent symbols. These data are reproduced from Ref. 24 for Ge-Sb-Se and Ge-Ga-Sb-S glasses; Ref. 41 for Ge-Sb-S-Se glasses.

를 나타내지만(Fig. 4(c)) 평균 결합에너지에 대해서는 뚜렷하게 낮은 상관관계를 보인다(Fig. 5(c)). 이러한 결 과를 바탕으로 열팽창 특성은 유리구조에 관여하는 화 학결합의 에너지 측면보다는 유리구조의 연결도 측면에 더 크게 영향을 받는 것으로 분석할 수 있다.

$\mathrm{Ge}$ 원자는 구성 성분 중에서 열적/기계적 물성에 가 장 큰 영향을 미치는 것으로 관찰되었으며, 이는 $\mathrm{Ge}$ 원 자의 배위수가 가장 크며 형성하는 화학결합의 결합에 너지가 높은 경향을 나타내기 때문에 유리구조의 에너 지 측면과 연결도 측면을 동시에 강화시키는 것으로 분 석된다. 이에 따라 삼성분계 $\mathrm{Ge}-\mathrm{Sb}-\mathrm{Se}$ 유리의 열적/ 기계적 물성은 $\mathrm{Ge}$ 함량의 조절을 통하여 가장 용이하게 제어될 수 있으며, 여타 칼코지나이드 유리 시스템에서 도 열적/기계적 물성을 조절하기 위해서는 평균 배위수 및 평균 결합에너지 관점에서 조성비를 제어하는 접근 이 유용한 것으로 판단된다.

\section{3-2. 광학적 물성의 조성 의존성}

칼코지나이드 유리를 결상용 광학렌즈로 사용하기 위 해서는 기본적으로 해당 파장대역에서의 광학적 투과도 가 보장되어야 하며, 굴절률 및 굴절률 분산을 파악하 는 것이 중요하다. 전형적인 유리소재와 같은 유전체의 굴절률은 Clausius-Mossotti 모델에 근거하여 원자 분 극률과 충진율을 활용하여 설명할 수 있다 ${ }^{38)}$. Fig. 6에
$\mathrm{Ge}-\mathrm{Sb}-\mathrm{Se}$ 유리와 $\mathrm{Ge}-\mathrm{Sb}-\mathrm{Se}-\mathrm{S}$ 유리의 파장에 대한 굴절률을 도시하였다. $\mathrm{Sb}$ 원자가 $\mathrm{Ge}$ 원자보다 분극률이 크기 때문에 $\mathrm{Sb}$ 함량이 감소하고 $\mathrm{Ge}$ 함량이 증가하면서 굴절률은 감소하며, 이러한 경향은 분극률이 큰 $\mathrm{Se}$ 원자 를 대체하며 분극률이 작은 $\mathrm{S}$ 원자가 첨가되는 경우에도 동일하게 나타남을 알 수 있다. 따라서 칼코지나이드 유 리의 굴절률을 높이기 위해서는 분극률과 충진율 관점 에서 구성원자의 조성비를 제어하는 것이 중요하다 ${ }^{39,40)}$.

Fig. 6(a)는 셀레나이드 유리와 설파이드 유리가 적 외선 대역에서 서로 상이한 굴절률 분산 특성을 가지는 것을 보여준다. Lorentz oscillator 모델에 근거하면, 굴절률은 공명 흡수가 발생하는 파장을 전후로 급격하 게 변화하므로 전술한 바와 같이 설파이드 유리와 셀레 나이드 유리의 fundamental vibrational absorption transition이 발생하는 파장이 서로 다르기 때문에 이 와 같은 현상이 나타남을 알 수 있다 ${ }^{42)}$. 즉, 설파이드 유 리의 적외선 투과단은 $~ 12 \mu \mathrm{m}$ 근처에 형성되어 셀레나 이드 유리의 적외선 투과단보다 짧은 파장에서 나타나 며, 이에 따라 원적외선 대역에서의 굴절률 분산이 셀레 나이드 유리보다 더 크다. 한편, 다중포논 흡수에 의해 발생하는 적외선 투과단을 유리 조성의 함수로 설명하 기 위하여 유리구조 전체에서 나타나는 원자들 사이의 진동을 단일 평균 조화진동자(SAHO; single average harmonic oscillator)의 진동으로 모사할 수 있다는 모 


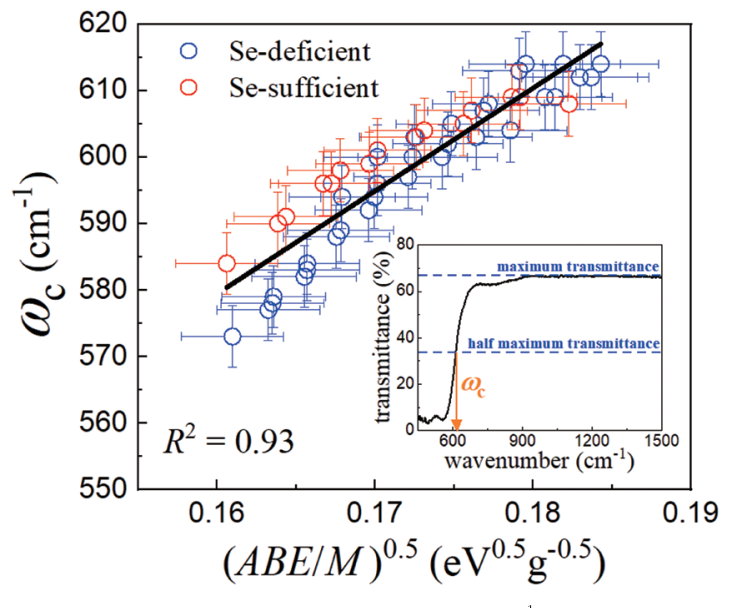

Fig. 7. Correlations between $\omega_{c}$ and $\left(\frac{A B E}{M}\right)^{\frac{1}{2}}$ for ternary Ge$\mathrm{Sb}-\mathrm{Se}$ glasses. Note that the inset shows how to define the position of $\omega_{c}$ in an infrared transmission spectrum. The data used in this plot are reproduced from Ref. 29.

델이 제안되었다 ${ }^{24)}$. 즉, $\mathrm{SAHO}$ 모델은 칼코지나이드 유 리가 가지는 적외선 투과단의 위치 $\left(\omega_{c}\right.$; 파수 단위 $)$ 가 해 당 유리의 평균 결합에너지와 몰 질량 $(M)$ 의 조합으로 표현될 수 있다는 것을 의미하며, Fig. 7에 도시한 바와 같이 삼성분계 $\mathrm{Ge}-\mathrm{Sb}-\mathrm{Se}$ 유리에서 $\omega_{c}$ 와 $\mathrm{SAHO}$ 인자 인 $\left(\frac{A B E}{M}\right)^{\frac{1}{2}}$ 사이의 상관관계가 0.93 수준의 매우 뛰어 난 선형성을 가진다는 사실이 실험적으로 규명되었으며 29), 나아가 $\mathrm{S}, \mathrm{Se}, \mathrm{Te}$ 를 모두 포함하는 전체 칼코지나이 드 유리에서도 Fig. 8과 같이 양호한 상관관계를 확인하 여 $\mathrm{SAHO}$ 모델의 보편성을 검증한 바 있다 ${ }^{43)}$. 따라서 이 러한 결과를 바탕으로 적외선 투과단 또한 조성의 함수 로써 예측할 수 있으며, 전술한 바와 같이 흡수와 굴절 률 분산의 상관관계에 근거하여 굴절률 분산 또한 조성 의 함수로 거동을 설명할 수 있다 ${ }^{24)}$.

\section{4. 칼크지나이드 유리의 조성제어 사례}

앞에서 삼성분계 $\mathrm{Ge}-\mathrm{Sb}-\mathrm{Se}$ 시스템을 대상으로 각 구성원자 사이의 상대 조성비 변화에 대한 물성의 변화 를 관찰하고 분석한 결과를 바탕으로 각 물성의 조성 의 존성을 파악한 결과를 기술하였고 유리구조를 대변하는

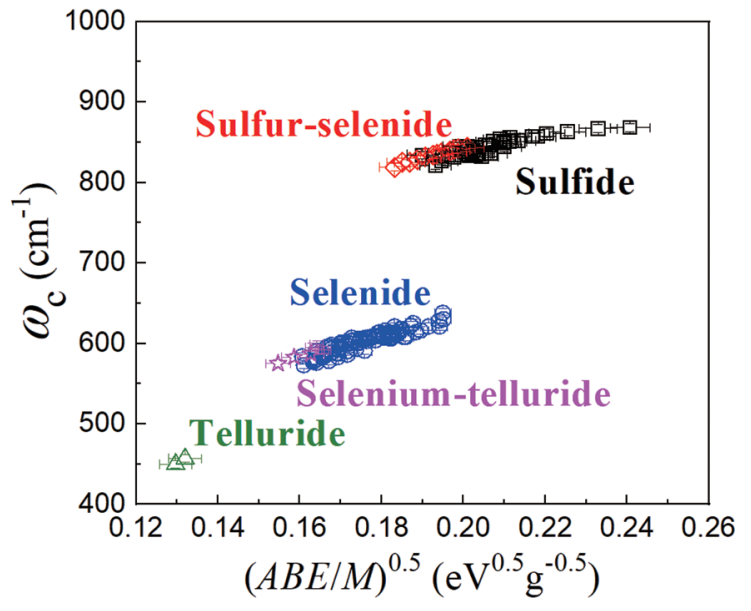

Fig. 8. The $\omega_{c}$ values plotted against $\left(\frac{A B E}{M}\right)^{\frac{1}{2}}$ for Ge-based chalcogenide glasses. Note that the data used in this plot are reproduced from Ref. 43.

평균 배위수와 평균 결합에너지 관점에서 물성제어 방 법론을 소개하였다. 여기에서는 삼성분계 시스템에 넷 째 성분을 첨가하여 추가적으로 물성을 조절하는 사례 를 소개하고자 한다. 이와 같은 조성제어를 통하여 열 적, 기계적, 광학적 물성을 원하는 방향으로 조절하였으 며, 특히 광학적 물성의 경우 다양한 굴절률 및 분산을 가지는 유리 조성들을 추가함으로써 원적외선 대역 아 베 다이어그램(Abbe diagram)을 더욱 확장시키고자 하 였다.

\section{4-1. Ge-Ga-Sb-Se 유리}

삼성분계 $\mathrm{Ge}-\mathrm{Sb}-\mathrm{Se}$ 유리에서 $\mathrm{Sb}$ 원자는 $\mathrm{Sb}-\mathrm{Se}$ 이 종결합을 형성하며 trigonal pyramid 형태로 유리구조 의 기본 뼈대에 참여하기 때문에 열적/기계적 물성 및 유리의 안정성 향상에 기여하지만, 전술한 바와 같이, $\mathrm{Ge}$ 원자와 비교하여 배위수와 결합에너지가 상대적으 로 작아서 거시적 물성의 증감에 미치는 영향이 적은 것 으로 분석된다. 이러한 관점에서 $\mathrm{Sb}$ 원자보다 유리구조 의 연결도 및 결합에너지를 효과적으로 향상시킬 수 있 는 네 번째 성분을 선정하고 첨가하여 $\mathrm{Ge}-\mathrm{Sb}-\mathrm{Se}$ 유리 의 열적/기계적 물성을 추가적으로 향상시키고자 하였 다. $\mathrm{Ga}$ 원자는 칼코지나이드 유리 내에서 '8-N 규칙'을 

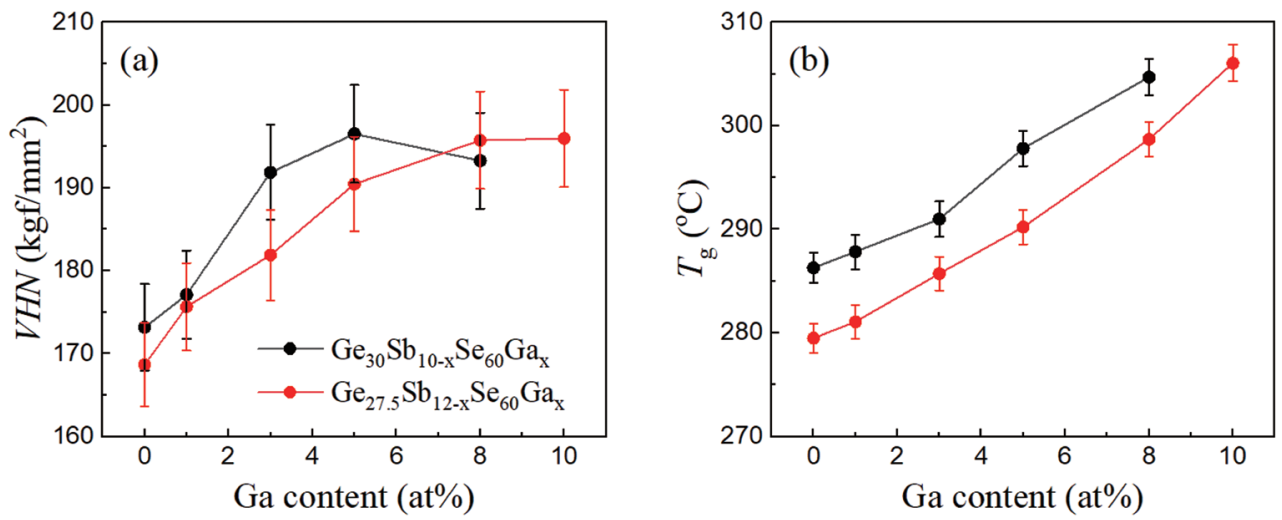

Fig. 9. (a) Micro-Vickers hardness and (b) glass transition temperature plotted as a function of Ga content in quaternary Ge-Ga$\mathrm{Sb}-\mathrm{Se}$ glasses.

위배하며 tetrahedron 구조를 형성하는 것으로 알려져 있으며 ${ }^{44)}, \mathrm{Ga}-\mathrm{Se}$ 결합에너지 또한 $2.39 \mathrm{eV}$ 로서 $\mathrm{Sb}-$ $\mathrm{Se}$ 결합에너지 $1.91 \mathrm{eV}$ 보다 높은 것으로 확인된다 ${ }^{36,37)}$. 이를 근거로 $\mathrm{Sb}$ 원자를 대체하여 $\mathrm{Ga}$ 원자를 첨가하였고 $\mathrm{Ga}$ 함량에 대한 대표적인 물성의 변화를 Fig. 9에 도시 하였다. $\mathrm{Ge}-\mathrm{Sb}-\mathrm{Se}$ 유리에서 $\mathrm{Sb}$ 함량이 $10 \mathrm{at} \%$ 인 모 조성에서 $\mathrm{Sb}$ 함량을 $\mathrm{Ga}$ 원자로 대부분 치환하였을 때도 유리가 형성되며 비커스 경도와 유리 전이온도 모두 뚜 렷하게 향상됨을 확인할 수 있다.

\section{4-2. Ge-Sb-S 유리 및 $\mathrm{Ge}-\mathrm{Ga}-\mathrm{Sb}-\mathrm{S}$ 유리}

셀레나이드 유리는 기본적으로 LWIR 아베 수(Abbe number; $v_{10}$ )가 100 이상의 값을 나타내므로 공히 저 분산 특성의 유리로 분류할 수 있다 ${ }^{45-47)}$. 따라서 고성 능 광학계의 구현을 위해서는 기존 저분산성 렌즈와 더 불어 고분산성 렌즈의 확보가 필요하다. 원적외선 대역 에서 고분산 특성은 전술한 바와 같이 적외선 투과단을 $12 \mu \mathrm{m}$ 에 가깝게 위치하도록 조절함으로써 구현할 수 있 으며, 이를 기반으로 Se 원자를 S 원자로 완전히 대체한 삼성분계 $\mathrm{Ge}-\mathrm{Sb}-\mathrm{S}$ 조성계가 고분산성 유리 후보로 채 택되었다. 그러나 삼성분계 $\mathrm{Ge}-\mathrm{Sb}-\mathrm{S}$ 유리는 $\mathrm{Ge}-\mathrm{Sb}-$ $\mathrm{Se}$ 유리와 비교하여 유리형성 영역이 상대적으로 좁기 때문에 구성원자 중에서 S 원자의 함량이 $60 \mathrm{~mol} \%$ 수 준으로 고정되는 경향을 나타낸다 ${ }^{22)}$. 이러한 조성범위 를 가지는 유리의 투과 스펙트럼은, Fig. 10(a)에 제시
한 바와 같이, $\mathrm{Ge}$ 함량이 증가하면서 $12 \mu \mathrm{m}$ 대역에 위 치한 적외선 투과단이 짧은 파장으로 이동함과 동시에 $\sim 9 \mu \mathrm{m}$ 대역에 산소 원자와 ${ }^{48)} \mathrm{Ge}$ 원자에 ${ }^{49)}$ 관련된 흡수 가 추가적으로 형성되는 경향이 관찰된다. 이를 바탕으 로 삼성분계 $\mathrm{Ge}-\mathrm{Sb}-\mathrm{S}$ 유리에서 $\mathrm{Ge}$ 함량 증가는 원적 외선 대역 투과도 저하를 유발함을 알 수 있으며, 원적 외선 대역 광학렌즈로의 응용을 위해서는 $\mathrm{Ge}$ 함량이 $15 \mathrm{~mol} \%$ 이하 수준으로 제한되어야 함을 의미한다. 그 러나 전술한 바와 같이 $\mathrm{Ge}$ 함량은 칼코지나이드 유리의 열적/기계적 물성에 매우 큰 영향을 미치기 때문에 낮 은 $\mathrm{Ge}$ 함량에 의해 수반되는 열적/기계적 물성의 저하 를 넷째 성분을 첨가하여 방지하고자 하였다. 넷째 원 소를 선별하기 위하여 1) Sb 원자보다 배위수가 크고 2) $\mathrm{Se}$ 원자와의 이종결합 에너지가 커야 한다는 기준을 적 용하였으며, 추가적으로 3) Sb 원자가 구성 성분 중에서 굴절률에 가장 큰 기여를 보이기 때문에 굴절률의 저하 또한 방지하고자 $\mathrm{Ga}, \mathrm{Bi}^{51)}, \mathrm{In}^{52)}, \mathrm{Sn}^{53)}$ 을 선정하여 시 편을 제작하고 물성 변화를 관찰하였다. Fig. 10(b)에서 확인할 수 있듯이 $\mathrm{Ga}, \mathrm{Bi}, \mathrm{In}$ 원자의 첨가 함량에 따라 경도가 증가하였으나, 이와 반대로 $\mathrm{Sn}$ 원자의 첨가는 경도를 저하시키는 경향을 나타낸다. 한편, Fig. 10(c)에 도시한 바와 같이 결정화 현상에 대한 영향을 함께 분석 하였을 때 $\mathrm{Ga}$ 원자가 유일하게 결정화에 대한 안정성을 향상시킴에 따라 가장 적합한 원소로 선정되었다. 결론 적으로 Fig. 11에서 볼 수 있듯이 적외선 광학렌즈로의 

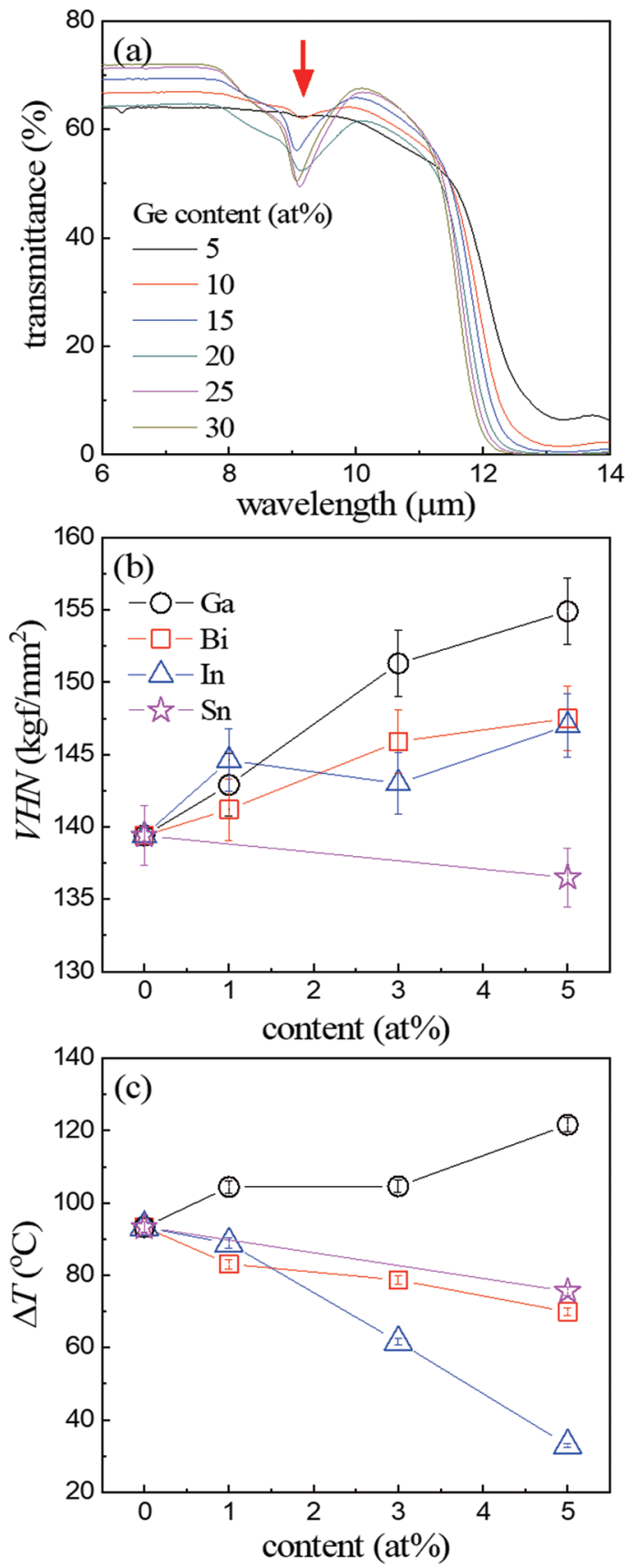

Fig. 10. (a) Infrared transmission spectra of $\mathrm{Ge}_{x} \mathrm{Sb}_{40-x} \mathrm{~S}_{60}$ glasses with thickness of $2 \mathrm{~mm}$. (b) Micro-Vickers hardness and (c) thermal stability of $\mathrm{Ge}_{5} \mathrm{X}_{x} \mathrm{Sb}_{35-}$ ${ }_{x} S_{60}$ glasses plotted as a function of the fourth constituent ( $X=\mathrm{Ga}$, Bi, In or $\mathrm{Sn}$ ). Note that the data utilized in these plots are reproduced from Ref. 50.

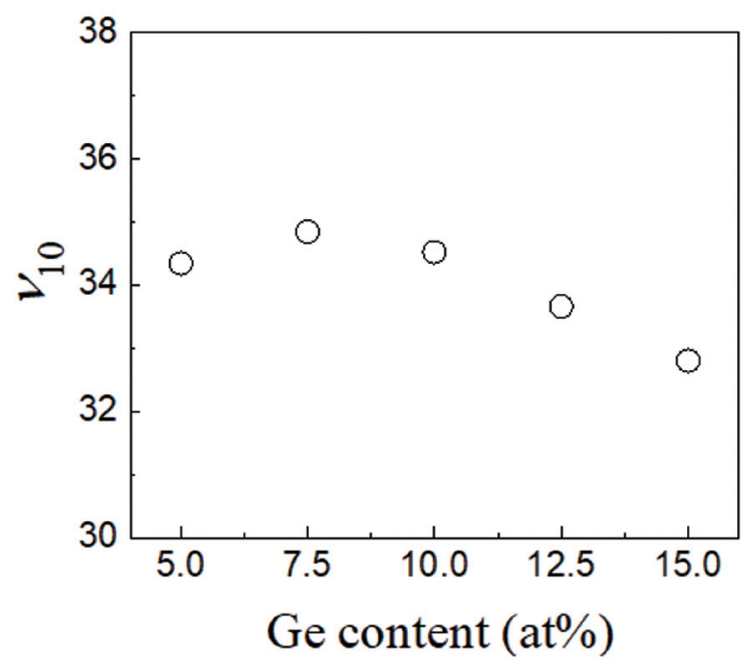

Fig. 11. LWIR Abbe numbers of $\mathrm{Ge}_{x} \mathrm{Ga}_{5} \mathrm{Sb}_{35-x} \mathrm{~S}_{60}$ glasses, which are reproduced from Ref. 50.

응용을 목적으로 34 수준의 LWIR 아베 수를 가지는 고분산성 칼코지나이드 유리를 확보하였으며, 이와 같 은 조성제어를 통해 원적외선 대역의 투과도가 보장되 고 기존 삼성분계 $\mathrm{Ge}-\mathrm{Sb}-\mathrm{S}$ 유리보다 열적/기계적 물 성 및 열적 안정성이 동시에 보완된 사성분계 $\mathrm{Ge}-\mathrm{Ga}-$ $\mathrm{Sb}-\mathrm{S}$ 유리 조성을 성공적으로 설계하였다 ${ }^{24)}$.

\section{4-3. Ge-Sb-S-Se 유리}

위에서 기술한 저분산성 $\mathrm{Ge}-\mathrm{Sb}-\mathrm{Se}$ 유리와 고분산성 $\mathrm{Ge}-\mathrm{Ga}-\mathrm{Sb}-\mathrm{S}$ 유리의 경우, 조성변화에 따라 굴절률이 상대적으로 큰 폭으로 변하는 반면에(Fig. 6) 두 조성 시 스템 공히 칼코진 원자의 함량이 $60 \mathrm{~mol} \%$ 수준으로 고 정되었기 때문에 굴절률 분산의 변화는 상대적으로 크 지 않게 된다. 이에 따라 기존 셀레나이드 유리와 설파 이드 유리의 중간에 위치하는 분산 특성을 가지면서 조 성변화 대비 굴절률 분산의 변화량이 큰 조성범위를 확 보하기 위하여 혼합 칼코진 조성계인 sulfur-selenide 계 유리를 설계하였다. 삼성분계 $\mathrm{Ge}-\mathrm{Sb}-\mathrm{Se}$ 유리에 $\mathrm{Se}$ 원자를 대체하여 $\mathrm{S}$ 원자를 첨가하는 방식으로 설계된 조성 시리즈의 열적/기계적 물성 변화를 Fig. 12 (a) 및 12 (b)에서 확인할 수 있다. 기본적으로 S 원자와 $\mathrm{Se}$ 원 자는 동일하게 2 배위를 가지기 때문에 해당 유리구조의 

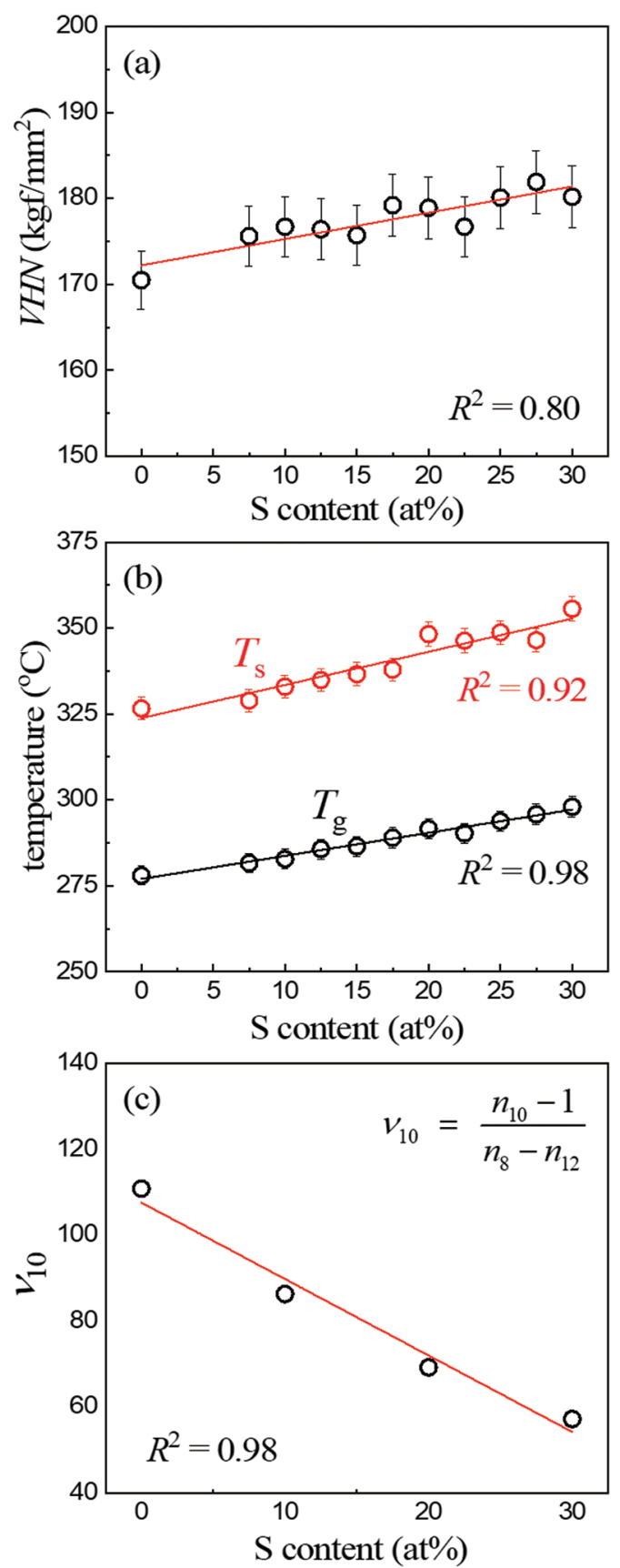

Fig. 12. Influences of $\mathrm{S}$ content in quaternary $\mathrm{Ge}_{27.5} \mathrm{Sb}_{12.5} \mathrm{Se}_{60-x} \mathrm{~S}_{x}$ glasses on (a) micro-Vickers hardness, (b) temperatures for glass transition and softening and (c) LWIR Abbe number. Note that the straight lines are obtained from least-squares fit to linear line, and the data used in these plots are reproduced from Ref. 41.
토폴로지 측면은 일정하게 유지되나 결합에너지 측면 에서 $\mathrm{S}$ 원자가 형성하는 $\mathrm{Ge}-\mathrm{S}$ 결합 $(2.32 \mathrm{eV})$ 과 $\mathrm{Sb}-\mathrm{S}$ 결합 $(2.07 \mathrm{eV})$ 의 이종결합 에너지가 $\mathrm{Se}$ 원자가 형성하 는 $\mathrm{Ge}-\mathrm{Se}$ 결합 $(2.14 \mathrm{eV})$ 및 $\mathrm{Sb}-\mathrm{Se}$ 결합 $(1.91 \mathrm{eV})$ 대 비 뚜렷하게 크기 때문에 제반 물성은 $\mathrm{S}$ 함량에 비례하 여 향상되는 결과를 나타낸다 $36,37,54-56)$. 이와 같은 방식 으로 설계된 사성분계 $\mathrm{Ge}-\mathrm{Sb}-\mathrm{S}-\mathrm{Se}$ 유리의 굴절률 분 산이 S 함량에 따라서 점진적으로 변화하는 거동을 Fig. 12 (c)에서 확인할 수 있다. 결과적으로 기존 $\mathrm{Sb}-\mathrm{Sb}-\mathrm{Se}$ 유리에서 $\mathrm{S} / \mathrm{Se}$ 비율을 제어함으로써 해당 유리의 열적/ 기계적 물성, 굴절률 및 분산을 조절할 수 있음을 알 수 있다.

\section{4-4. LWIR 아베 다이어그램}

본 연구진이 확보한 삼성분계 $\mathrm{Ge}-\mathrm{Sb}-\mathrm{Se}$ 유리의 분 산은 기존 상용 유리조성과 유사하게 $v_{10}>100$ 수준의 저분산 특성을 가지며, 사성분계 $\mathrm{Ge}-\mathrm{Ga}-\mathrm{Sb}-\mathrm{S}$ 유리 는 $v_{10} \approx 34$ 수준의 뚜렷한 고분산 특성을 나타내는 반면 에 $\mathrm{Ge}-\mathrm{Sb}-\mathrm{S}-\mathrm{Se}$ 유리는 $\mathrm{S} / \mathrm{Se}$ 비율에 따라 $34<v_{10}<$ 100 범위에서 분산 특성이 제어될 수 있다. 이와 같은 조성제어 방법론을 활용하여 5 종의 원자 $(\mathrm{Ge}, \mathrm{Sb}, \mathrm{Ga}$, $\mathrm{S}, \mathrm{Se}$ )를 조합하여 저분산 영역부터 고분산 영역에 이르 는 넓은 범위의 분산 특성을 구현할 수 있으며, Fig. 13 에 도시한 바와 같이 저분산 영역에 국한되어 있던 기 존 상용 칼코지나이드 유리 기반 원적외선 대역 아베 다 이어그램을 본 연구진이 확보한 유리 조성을 추가함으 로써 고분산 영역까지 현저하게 확장시킬 수 있다. 기존 상용 조성들은 공통적으로 해당 조성계에서 열적/기계 적 물성을 우선적으로 고려하여 조성이 선정되었으며, 따라서 광학적 특성은 부수적으로 결정되었다. 그러나 이와는 반대로 본 연구진은 특정 광학적 물성의 확보를 목표로 조성설계를 진행하여 세계최초로 고분산 특성의 칼코지나이드 유리를 확보하였다 ${ }^{24,50)}$. 또한, 시행착오 적 반복실험에 주로 의존하던 기존 조성 최적화 방법론 에서 벗어나 유리구조를 대변하는 반경험적 구조인자를 활용하여 물성변화를 파악하는 새로운 조성제어 방법론 을 창안함으로써 임의의 칼코지나이드 조성계를 대상으 


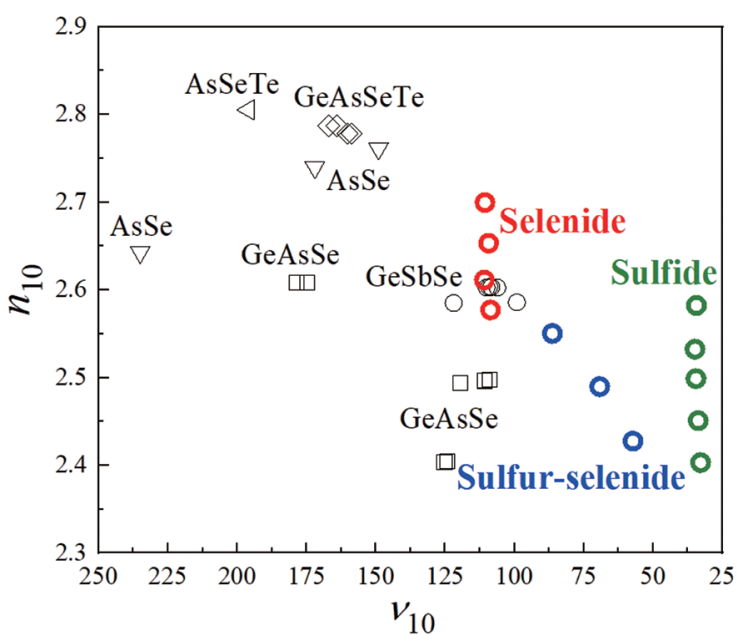

Fig. 13. LWIR Abbe diagram incorporating commercially available chalcogenide glasses (distinguished in black color) and the compositionally engineered glasses (distinguished in red, blue and green). Note that the data used in this plot are reproduced from Ref. 41.

로 비교적 정량적으로 조성을 선별할 수 있도록 하였다 ${ }^{29)}$.

\section{5. 요약 및 제언}

본 논문에서는 원적외선 대역 결상용 광학렌즈 응용 을 위한 칼코지나이드 유리소재의 조성 최적화 사례를 삼성분계 $\mathrm{Ge}-\mathrm{Sb}-\mathrm{Se}$ 유리를 중심으로 소개하였다. 열 화상 카메라에 대한 민수분야의 수요 증가에 대응하 기 위해서는 광학렌즈의 고성능화 및 소형화와 함께 가 격 경쟁력 확보가 매우 중요하다. 기존 상용 칼코지나이 드 유리 조성들이 비교적 제한된 범위의 광학적 물성지 표를 보이기 때문에 원적외선 대역 결상 광학계의 추가 적 성능 향상을 위하여 보다 넓은 범위의 굴절률 및 분 산을 가지며 적절한 온도수차를 보이는 신규 유리조성 들이 필요하다. 또한, 기존 상용 조성들에는 $\mathrm{As}$ 및 $\mathrm{Sb}$ 와 같은 성분이 포함되어 있기 때문에 향후 민수시장의 안 정적 확대를 위하여 보다 환경 친화적인 신규 조성들이 필요하며, 동시에 저가의 원료물질을 위주로 유리상을 형성하는 조성계 역시 필요하다. 렌즈성형 공정 측면에 서는 공정단가를 낮추기 위하여 기존 PGM 공정에 추가 하여 웨이퍼 레벨 몰딩(또는 임프린팅) 공정에 대한 관
심이 증대되고 있다. 웨이퍼 레벨 몰딩 공정은 전형적인 PGM 공정과 차별되는 열간 변형특성을 요구하며 따라 서 이에 최적화된 조성 역시 필요한 상황이다.

기존 상용 조성들은 공히 열적/기계적 안정성 위주로 세부 조성비가 결정되어서 광학적 물성 관점에서 활용 가능한 조성의 숫자가 제한적이기 때문에 앞으로는 렌 즈 성형공정 측면에서의 요구사항과 렌즈의 광학적 특 성 측면에서의 요구사항을 우선적으로 반영하는 조성 최적화 역시 필요하다. 이를 위해서는 칼코지나이드 유 리의 열적/기계적/광학적 특성의 조성 의존성을 직간접 적으로 예측할 수 있게 하는 실험적/이론적 근거가 더욱 축적되어야 하며, 본 논문에 소개한 사례가 이러한 노력 의 일환을 보여준다.

\section{Acknowledgements}

본 연구는 산업통상자원부의 소재부품기술개발사업 (No. 20010481)과 한국연구재단의 기초연구사업(No. 2018R1D1A1B07040938)의 지원을 받아 수행되었습니다.

\section{REFERENCES}

1. H.Y. Kim and T.H. Kim, "Materials for Thermal Imager and Application Trend (in Korean)," Ceramist, 17[4] 61-71 (2014).

2. J.W. Lee, "Development Trend and Applications of SWIR Image Sensor (in Korean)," Ceramist, 21[2] 59-74 (2018).

3. A. Rogalski and K. Chrzanowski, "Infrared Devices and Techniques," Metrol. Meas. Syst., 21[4] 565-618 (2014).

4. D.C. Harris, Materials for Infrared Window and Domes: Properties and Performance, SPIE-the International Society for Optical Engineering, Washington, 1999.

5. T.L. Williams, Thermal Imaging Cameras: Characteristics and Performance, CRC Press, New York, 2019.

6. A. Graham, R.A. Leblanc and R. Hilton, "Low Cost Infrared Glass for IR Imaging Applications," Proc. 
SPIE., 5078 216-224 (2003).

7. S. Moustakidis, A. Anagnostis, P. Karlsson and K. Hrissagis, "Non-destructive Inspection of Aircraft Composite Materials using Triple IR Imaging," IFACPapers Online, 49 291-296 (2016).

8. F. Ciampa, P. Mahmoodi, F. Pinto and M. Meo, "Recent Advances in Active Infrared Thermography for Non-destructive Testing of Aerospace Components," Sensors, 18609 (2018).

9. A. Szajewska, "Development of the Thermal Imaging Camera (TIC) Technology," Procedia Eng., 172 10671072 (2017).

10. G.G. Hallock, "Dynamic Infrared Thermography and Smartphone Thermal Imaging as an Adjunct for Preoperative, Intraoperative, and Postoperative Perforator Free Flap Monitoring," Plast. Aesthet. Res., 629 (2019).

11. A. Bourget, Y. Guimond, J. Frank and M.V.D. Bergh, "Moulded Infrared Optics Making Night Vision for Cars within Reach," Proc. SPIE., 5663 182-189 (2003).

12. G. Curatu, "Design and Fabrication of Lowcost Thermal Imaging Optics Using Precision Chalcogenide Glass Molding," Proc. SPIE., 7060 706008 (2008).

13. H. Wang, Y. Cai, X. Chen and L. Chen, "Night-time Vehicle Sensing in Far Infrared Image with Deep Learning," J. Sens., 2016 1-8 (2016).

14. H. Peter, M.D. Lin and M.D.M. Saines, “Assessment of Lower Extremity Ischemia using Smartphone Thermographic Imaging," J. Vasc. Surg. Cases Innov. Tech., 3[4] 205-208 (2017).

15. M. Vollmer and K.P. Möllmann, "Infrared Cameras as Accessories to Smartphones: Facts You Need to Know," Phys. Educ., 53[6] 065019 (2018).

16. A. Rogalski, "Next Decade in Infrared Detectors," Proc. SPIE., 10433 104330L1-25 (2017).

17. X.H. Zhang, Y. Guimend and Y. Bellec, "Production of Complex Chalcogenide Glass Optics by Molding for Thermal Imaging," J. Non-Cryst. Solids, 326-327 519-523 (2003).

18. X. Zhang, H. Ma and J. Lucas, "Applications of Chalcogenide Glass Bulks and Fibres," $J$. Optoelectron. Adv. Mater., 5 1327-1333 (2003).

19. J. Huddleston, A. Symmons and R. Pini, "Comparison of the Thermal Effects on LWIR Optical Designs
Utilizing Different Infrared Optical Materials," Proc. SPIE., 9070 90702E1-12 (2014).

20. L. Vandeperre, F. Giuliani, S. Lloyd and W. Clegg, "The Hardness of Silicon and Germanium," Acta Mater, 55 6307-6315 (2007).

21. C.A. Klein and J. Pappis, " $\mathrm{ZnS}, \mathrm{ZnSe}$, and $\mathrm{ZnS} /$ ZnSe Windows: Their Impact on FLIR System Performance," Opt. Eng., 25 254519-254519 (1986).

22. M.A. Popescu, Non-Crystalline Chalcogenides, Kluwer Academic Publishers, New York, 2002.

23. E. Hecht, Optics, 5th ed., Pearson Education, Inc., USA, 2017.

24. J.H. Lee, J.H. Choi, J.H. Yi, W.H. Lee, E.S. Lee and Y.G. Choi, "Unravelling Interrelations between Chemical Composition and Refractive Index Dispersion of Infrared-transmitting Chalcogenide Glasses," Sci. Rep., 815482 (2018).

25. E.J. Fernandez and P. Artal, "Achromatic Doublet Intraocular Lens for Full Aberration Correction," Biomed. Opt. Express, 8[5] 2396-2404 (2017).

26. A.R. Hilton, Chalcogenide Glasses for Infrared Optics, McGraw-Hill, New York, 2010.

27. E.A. Braude and F.C. Nachod, Determination of Organic Structures by Physical Methods, Academic Press, Inc., New York, 1955.

28. P. Lucas, G.J. Coleman, S. Jiang, T. Luo and Z. Yang, "Chalcogenide Glass Fibers: Optical Window Tailoring and Suitability for Bio-chemical Sensing," Opt. Mater., 47 530-536 (2015).

29. J.H. Lee, H. Kim and Y.G. Choi, "Compositional Screening of Chalcogenide Glass for Use as Molded Lens: An Exemplary Case of Ternary Ge-Sb-Se Glass (invited article)," J. Asian Ceram. Soc., (2020) under revision.

30. J.H. Lee, W.H. Lee, J.K. Park, J.H. Yi, S.Y. Shin, B.J. Park, B.J. So, J. Heo, J.H. Choi, H.J. Kim and Y.G. Choi, "Thermal Properties of Ternary Ge-SbSe Chalcogenide Glass for Use in Molded Lens Applications," J. Non-Cryst. Solids, 431 41-46 (2016).

31. J.K. Park, J.H. Lee, S.Y. Shin, J.H. Yi, W.H. Lee, N.Y. Kim and Y.G. Choi, "Compositional Dependence of Hardness of Ge-Sb-Se Glass for Molded Lens Applications" Arch. Metall. Mater., 60 1205-1208 (2015).

32. W.H. Lee, J.H. Yi, J.H. Lee, B.J. Park, J.H. Choi, H.J. Kim and Y.G. Choi, "Thermal Expansion Behavior 
of Ge-Sb-Se Glasses in a Compositional Range for Molded Infrared Lens Applications," Int. J. Appl. Glass Sci., 8 226-232 (2017).

33. J.H. Lee, J.H. Yi, W.H. Lee, B.J. Park and Y.G. Choi, "Crystallization Behavior of Ge-Sb-Se Glasses in the Compositional Range for Use as Molded Lenses," $J$. Non-Cryst. Solids, 481 21-26 (2018).

34. Z.G. Ivanova, V. Pamukchieva and M. Vlček, "On the Structural Phase Transformations in $\mathrm{Ge}_{x} \mathrm{Sb}_{40}$ ${ }_{x} \mathrm{Se}_{60}$ glasses," J. Non-Cryst. Solids, 293-295 580-585 (2001).

35. L. Tichý and H. Tichá, "Covalent Bond Approach to the Glass-transition Temperature of Chalcogenide Glasses," J. Non-Cryst. Solids, 189 141-146 (1995).

36. L. Pauling, Nature of the Chemical Bond, 3rd ed., Cornell Univ. New York, 1960.

37. R.T. Sanderson, "Bond Energies," J. Inorg. Nucl. Chem., 28 1553-1565 (1966).

38. R.D. Shannon, "Dielectric Polarizabilities of Ions in Oxides and Fluorides," J. Appl. Phys., 73 348-366 (1993).

39. P. Hartmann, R. Jedamzik, S. Reichel and B. Schreder, "Optical Glass and Glass Ceramic Historical Aspects and Recent Developments: A Schott View," Appl. Opt., 49 157-176 (2010).

40. D.R. Lide. CRC Handbook of Chemistry and Physics: A Ready-reference Book of Chemical and Physical Data, 84th ed., CRC Press, New York, 2004.

41. J.H. Lee, H. Kim, J.I. Lee, S.Y. Ko, J.H. Choi and Y.G. Choi, "Infrared Transmission and Refractive Index Dispersion of Mixed-chalcogen Ge-Sb-S-Se Glasses for Use in Molded Lens Applications," $J$. Non-Cryst. Solids, 546120258 (2020).

42. T. Yoshizawa, Handbook of Optical Metrology: Principles and Applications, 2nd ed., CRC Press, London, 2009.

43. H. Kim, J.H. Lee, J.I. Lee, S.Y. Ko and Y.G. Choi, "Compositional Dependence of Infrared Transmission in Ge-based Chalcogenide Glasses," Phys. Status Solidi B, 2000164 1-5 (2020).

44. R. Golovchak, L. Calvez, E. Petracovschi, B. Bureau, D. Savytskii and H. Jain, "Incorporation of Ga into the Structure of Ge-Se Glasses," Mater. Chem. Phys., 138 909-916 (2013).

45. A. Feltz, W. Burckhardt, B. Voigt and D. Linke,
“Optical Glasses for IR Transmittance," J. Non. Cryst. Solids, 129 31-39 (1991).

46. J.A. Savage, P.J. Webber and A.N. Pitt, "Infrared Optical Glasses for Applications in 8-12 $\mu \mathrm{m}$ Thermal Imaging Systems," Appl. Opt., 16 2938-2941 (1977).

47. J.L. Adam and X. Zhang, Chalcogenide Glasses: Preparation, Properties and Applications, Woodhead Publishing Limited, Cambridge, 2014.

48. T.S. Kavetskyy, A.P. Kovalskiy, V.D. Pamukchieva and O.I. Shpotyuk, "IR Impurity Absorption in $\mathrm{Sb}_{2} \mathrm{~S}_{3}$ $\mathrm{GeS}_{2}\left(\mathrm{Ge}_{2} \mathrm{~S}_{3}\right)$ Chalcogenide Glasses," Infrared Phys. Technol., 41 41-45 (2000).

49. E.I. Kamitsos, J.A. Kapoutsis, G.D. Chryssikos, G. Taillades, A. Pradel and M. Ribes, "Structure and Optical Conductivity of Silver Thiogermanate Glasses," J. Solid State Chem., 112 255-261 (1994).

50. J.H. Lee, W.H. Lee, J.H. Choi and Y.G. Choi, "High Refractive Index Dispersion of Compositionally Optimized Ge-Ga-Sb-S Sulfide Glass for Use as Molded Lens in the Long-Wavelength Infrared Range," Ceram. Int., 44 21956-21961 (2018).

51. J.C. Phillips, "Constraint Theory and Carrier-type Reversal in Bi-Ge Chalcogenide Alloy Glasses," Phys. Rev. B, 36[8] 4265-4270 (1987).

52. S. Mahadeva and A. Giridhar, "Charged Defectscontrolled Conductivity in Ge-In-Se Glasses," $J$. Mater. Sci., 29 3837-3842 (1994).

53. T. Fukunaga, Y. Tanaka and K. Murase, "Glass Formation and Vibrational Properties in the (Ge, Sn)Se System," Solid State Commun., 42[7] 513-516 (1982).

54. L. Petit, N. Carlie, R. Villeneuve, J. Massera, M. Couzi, A. Humeau, G. Boudebs and K. Richardson, "Effect of the Substitution of S for Se on the Structure and Non-linear Optical Properties of the Glasses in the System $\mathrm{Ge}_{0.18} \mathrm{Ga}_{0.05} \mathrm{Sb}_{0.07} \mathrm{~S}_{0.70-x} \mathrm{Se}_{x}$," J. Non-Cryst. Solids, 352 5413-5420 (2006).

55. B. Ye, S. Dai, R. Wang, G. Tao, P. Zhang, X. Wang and X. Shen, "Influence of the Selenium Content on Thermo-mechanical and Optical Properties of Ge-GaSb-S Chalcogenide Glasses," Infrared Phys. Technol., 77 21-26 (2016).

56. S.Y. Shin, J.H. Lee, H. Kim, H. Masai, T. Ina and Y.G. Choi, "Structural Evolutions of Mixed-Chalcogen $\mathrm{Ge}-\mathrm{Sb}-\mathrm{S}-\mathrm{Se}$ Glasses for Use as Infrared Lenses, Ceram. Int., 46 17809-27817 (2020). 


\section{ㅇㅇ이준 호

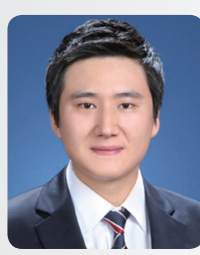 \\ ( 2007-2014년 한국항공대학교 항공재료공학과 학사 \\ ( 2014-2016년 한국항공대학교 항공재료공학과 석사 \\ - 2016-2020년 한국항공대학교 항공재료공학과 박사 \\ - 2020년-현재 한국항공대학교 박사후 연구원}

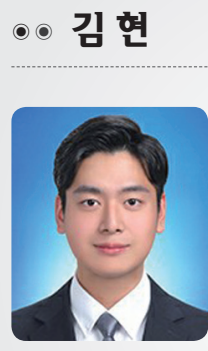

- 2009-2017년 한국항공대학교 항공재료공학과 학사

( 2017-2019년 한국항공대학교 항공재료공학과 석사

( 2019년-현재 한국항공대학교 항공재료공학과 박사과정

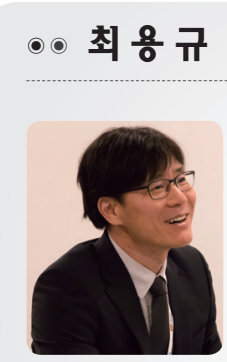

( 1987-1991년 KAIST 재료공학과 학사

○ 1992-1994년 POSTECH 신소재공학과 석사

- 1994-1998년 POSTECH 신소재공학과 박사

- 1998-2004년 한국전자통신연구원 원천기술연구본부 선임연구원

- 2000년 ORC, Southampton Univ. 영국 방문연구원

• 2010-2011년 IMI for Glass, Lehigh Univ. 미국 방문교수

- 2018년 Zhejiang Univ. 중국 방문교수

( 2004년-현재 한국항공대학교 항공재료공학과 조교수/부교수/교수 